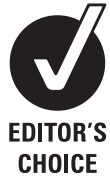

Royal North Shore Hospital, St Leonards, New South Wales, Australia

\section{Correspondence to}

Dr Natalie Purcell, 34 Pearl Bay Ave, Beauty Point, NSW 2088, Australia;

npur6572@med.usyd.edu.au

Received 21 June 2010

Accepted 1 January 2011

Published Online First

10 February 2011

\title{
Using the ISBAR handover tool in junior medical officer handover: a study in an Australian tertiary hospital
}

\author{
James E Thompson, Luke W Collett, Marc J Langbart, Natalie J Purcell, \\ Stephanie M Boyd, Yuigi Yuminaga, Gemma Ossolinski, Clarissa Susanto, \\ Ann McCormack
}

\begin{abstract}
Background Despite being essential to patient care, current clinical handover practices are inconsistent and error prone. Efforts to improve handover have attracted attention recently, with the ISBAR tool increasingly utilised as a format for structured handover communication. However, ISBAR has not been validated in a junior medical officer setting.
\end{abstract}

Objective To assess the effect of the ISBAR handover tool on junior medical officer (JMO) handover communication in an Australian hospital.

Methods JMOs who participated in after-hours handover during an 11 week clinical term from June to August 2009 were recruited. After-hours handover was audiotaped, and JMOs completed a survey to assess current handover perception and practice. JMOs then participated in a $1 \mathrm{~h}$ education session on handover and use of the ISBAR handover tool, and were encouraged to handover using this method. Following the education session, participants were surveyed to measure perceived changes in handover with use of ISBAR, and handover was again audiotaped to assess differences in information transfer and duration.

Results Following the introduction of ISBAR, 25/36 (71\%) of JMOs felt there was an overall improvement in handover communication. Specifically, they perceived improvement in the structure and consistency of handover, they felt more confident receiving handover, and they believed patient care and safety were improved. Audio-tape data demonstrated increased transfer of key clinical information during handover with no significant effect on handover duration.

Conclusions Use of the ISBAR tool improves JMO perception of handover communication in a time neutral fashion. Consideration should be given to the introduction of ISBAR in all JMO handover settings.

\section{INTRODUCTION}

Handover is defined as the transfer of professional responsibility and accountability for the care of a patient. ${ }^{1}$ With increasing focus on safe working hours, demand for part-time work and the move towards multidisciplinary patient care, handover is occurring more frequently. ${ }^{12}$ A recent Australian study estimated that patients see an average of 6-10 doctors per admission. ${ }^{3}$ However, current handover practices are criticised as being highly variable, unstructured, and error-prone. ${ }^{4}$ International evidence suggests few trainees receive formal instruction on the handover process, and it is unknown how many medical students and junior doctors in Australia currently receive training or evaluation in handover. ${ }^{5}$ Inadequate handover has implications for patient care and safety, with communication failures identified as the root cause in over $70 \%$ of adverse hospital events. ${ }^{6}$

A number of recommendations have been made on how to improve handover. These include ensuring a set time and place free of interruption, training sessions, senior supervision and use of electronic aids. ${ }^{1578}$ One important recommendation is that handover should follow a standardised approach, ${ }^{2} 9$ such as the framework designated by the acronym 'ISBAR' (figure 1).

The ISBAR tool may improve handover by providing a template which creates a clear picture of the patient's clinical issues while also defining outstanding issues and tasks. ${ }^{10}$ It aids communication by offering an expected pattern of transferred information so errors or omitted information become clear. $911{ }^{12}$ Studies on ISBAR have shown that it can have a substantial impact on improving the quality of handover. ${ }^{13}$ It is a well received, easy to remember tool, and has been shown to reduce rates of adverse events. ${ }^{12} 14$

Despite handover practice being widely discussed in the literature, there is no substantial evidence to justify changes in practice. ${ }^{15}$ Furthermore, there are no published studies focusing on the use of ISBAR in handover between junior doctors, and no well established evidence base for best practice in handover between JMOs. ${ }^{16} 17$ The aim of this study was to assess the effect of the ISBAR handover tool on clinical handover between JMOs in a tertiary hospital setting, in terms of JMO perception of handover, transfer of key clinical information, and duration of handover.

\section{METHODS}

The study was conducted at Royal North Shore Hospital (box 1) during an 11 week JMO clinical term from June to August 2009, following approval by the Northern Sydney Central Coast Human Research Ethics Committee. Forty-four JMOs (interns, residents, and medical registrars) rostered to after-hours handover during this period were asked to consent and participate in the study. Box 2 outlines overtime and handover practices at Royal North Shore Hospital. The ISBAR tool was selected for this study ahead of other handover tools as it is 


\section{SITUATION}

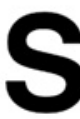

-Symptom/problem

Patient stability/evel of concern

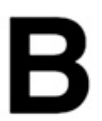

BACKGROUND

History of presentation

- Date of admission and diagnosis

- Relevant past medical hx

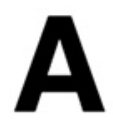

ASSESSMENT \& ACTION

-What is your diagnosis/

-What have you done so far?

$\mathbf{R}$

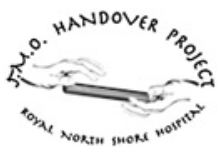

RESPONSE \& RATIONALE

-What you want done

- Treatment/investigations underway or that need monitoring

Review: by whom, when and of what?

- Plan depending on results/clinical

course
Figure 1 Explanation of the acronym 'ISBAR'.

the most extensively studied. ${ }^{18}$ The study was divided into three phases.

Phase 1: Collection of Pre-ISBAR baseline audiotape data (weeks 1-3) - In the first 3 weeks of the clinical term, baseline data were collected by audiotaping after-hours JMO handover meetings. The nine handover meetings which occur each week are supervised by the after-hours medical registrar, who was responsible for audiotaping handover during the study period.

Phase 2: Baseline survey and education session (weeks 4-7)-In phase 2, participants completed a baseline survey to assess their perception of existing handover practices (table 1). The survey contained eight statements to which the respondent was asked to agree or disagree according to a six point Likert scale, and participants were also asked to comment on how handover practices could be improved. Participants then attended a $1 \mathrm{~h}$ education session focusing on the importance of effective handover and use of the ISBAR communication

\section{Box 1 Royal North Shore Hospital}

- Royal North Shore Hospital (RNSH) is a 600 bed tertiary referral teaching hospital located in Northern Sydney, NSW, Australia.

- It has over 42000 presentations to the emergency department each year, and over 46000 patients admitted to hospital each year, with an average length of stay of 4.1 days.

- RNSH is a trauma centre and offers treatment in major specialty areas.

- RNSH is one of two spinal injury and burns referral centres in NSW. tool. The education session was held at four separate times to maximise JMO attendance, and also videotaped with a DVD provided to those JMOs who did not attend the session. Each session was conducted by the Director of Prevocational Education and Training at Royal North Shore Hospital, assisted by two study authors. Further, JMOs were provided with a card to remind them of the ISBAR acronym that readily attached to their hospital identification badge, and large posters were erected in the JMO handover room. Participants were given 3 weeks to gain familiarity and proficiency with the ISBAR tool and were encouraged to use the ISBAR tool at handover meetings.

Phase 3: Collection of post-ISBAR audiotape data and exit survey (weeks 8-11) - In phase 3, after-hours handover meetings were audiotaped for the last 4 weeks of the clinical term. During the final week of the study, all JMOs completed an exit survey containing seven of the same statements from the baseline survey and an additional four questions specifically addressing ISBAR and the education workshop (table 2).

\section{Data analysis and statistical methods}

The pre-ISBAR and post-ISBAR surveys were analysed with a Mann-Witney $U$ test to establish any change in JMO perception of handover.

Each audiotaped handover session was timed, and assessed for adequacy of clinical information communicated according to 19 core data categories (table 3), which were formulated by the study group before study commencement, and a proforma constructed for data collection. All tapes were analysed by two study authors to ensure consensus on data. The pre-ISBAR and post-ISBAR audiotape data were analysed using a two-sample $t$ test to establish any change in the duration of handover per patient as well as any change in the number of key data categories handed over per patient.

All results were externally validated. Significance was accepted at $\mathrm{p} \leq 0.05$.

\section{Study end points}

The primary study end point was JMO perception of an overall change in handover practice following implementation of the ISBAR tool. Secondary end points included change in perception of structure and consistency of handover, confidence in the handover process, and JMO impression on patient care and safety. Secondary end points from the audiotape data included change in the median number of core data categories communicated and change in the average duration of handover per patient.

\section{RESULTS}

Forty-four JMOs were rostered to after-hours handover during the study period; 28/44 (64\%) completed the baseline survey, and 36/44 (82\%) completed the exit survey. 24/44 (55\%) participants formally attended the education session, with the provision of recorded educational material to the other participants

\section{JMO perception on the effect of ISBAR on handover (survey data)}

$16 / 27(59 \%)$ of JMOs believed that a poor handover adversely affected their understanding of a patient's clinical picture. 25/35 (71\%) of JMOs felt that the ISBAR tool had improved handover and $20 / 25(80 \%)$ felt the handover workshop improved their skills and confidence in handover. 
Box 2 Overtime shifts and handover at Royal North Shore Hospital

- After hours, Royal North Shore Hospital (RNSH) is covered by intern and resident staff who are responsible for reviewing any unwell or deteriorating patients, updating patient charts, and also performing any specific tasks requested by the treating team. Each JMO covers 3-6 wards of approximately 25 patients each. The overtime shift lasts $6-8 \mathrm{~h}$.

- A medical registrar is in the hospital at all times to supervise and assist the intern and resident staff as needed. A medical emergency team (MET) consisting of intensive care and anaesthetic support is also available to assist with acute medical emergencies.

- At the end of each overtime shift, a formal face-to-face handover occurs in an assigned, private location. These occur at $10 \mathrm{pm}$ each evening and $8 \mathrm{am}$ on weekends or public holidays (nine handover sessions per week). The handover is supervised by the medical registrar. On weekdays, there is no formal morning handover-the night staff are responsible for contacting the relevant day team directly regarding any unwell patients.

- Handover typically lasts $15-30 \mathrm{~min}$, with between 10 and 20 patients handed over each session. Unwell patients requiring review as well as any outstanding tasks are handed over to the incoming doctor.

- The incoming doctor records details of the handover as he or she chooses, usually as short notes. No handover artefacts were in use at the time of this study.

- At the completion of the handover session, each overtime doctor is responsible for reviewing the patients which were handed over to them and completing any outstanding tasks.

- Approximately 40-50 interns and residents participate in overtime each clinical term (lasting 10-11 weeks), with each JMO participating in approximately one overtime shift per week.

Following the introduction of ISBAR, significantly more JMOs perceived handover as being consistent, better structured, and with less omission of information occurring (table 4). JMOs felt more aware of the urgency of patient situations and more confident in accepting care of patients handed over to them using the ISBAR format. There was no significant change in perception of whether the amount of information handed over was sufficient to meet their needs, or in the time efficiency of handover with ISBAR. Most participants indicated on the exit survey they felt ISBAR represented a sustainable system 26/36 $(72 \%)$ that improved patient care and safety $26 / 35$ (74\%).

JMOs were also encouraged to provide comments in their survey responses. When asked what was good about ISBAR, sample responses included: "the receiver knows what structure to expect during a handover and it helps to identify missing information" and "it reinforces what is key to a handover". Among responses regarding the disadvantages of ISBAR was concern about templates being "less flexible" and possibly less appropriate for "simple handovers such as chasing a blood test". It was suggested that ISBAR template handover sheets should be made available on the wards and in the handover room. One recurring comment was that JMOs would appreciate more constructive feedback from seniors on the quality of their handovers.
Table 1 Baseline survey

1) The current handover system is time efficient

$\begin{array}{lllllllll}\text { Strongly disagree } & 1 & 2 & 3 & 4 & 5 & 6 & \text { Strongly agree }\end{array}$

2) The current handover system is consistent for each patient

$\begin{array}{lllllllll}\text { Strongly disagree } & 1 & 2 & 3 & 4 & 5 & 6 & \text { Strongly agree }\end{array}$

3) Usually, the amount of information about each patient handed over to me is sufficient to meet my needs (neither too little nor too much)

$\begin{array}{lllllllll}\text { Strongly disagree } & 1 & 2 & 3 & 4 & 5 & 6 & \text { Strongly agree }\end{array}$

4) Critical patient information is often omitted at handover

$\begin{array}{lllllllll}\text { Strongly disagree } & 1 & 2 & 3 & 4 & 5 & 6 & \text { Strongly agree }\end{array}$

5) Patient information is often structured poorly during handover

$\begin{array}{lllllllll}\text { Strongly disagree } & 1 & 2 & 3 & 4 & 5 & 6 & \text { Strongly agree }\end{array}$ 6) My understanding of a patient's clinical picture is adversely affected by a poorly structured handover (even if all relevant information is included)

$\begin{array}{lllllllll}\text { Strongly disagree } & 1 & 2 & 3 & 4 & 5 & 6 & \text { Strongly agree }\end{array}$ 7) During most handovers, I am informed which patients are unstable or require more urgent attention.

$\begin{array}{lllllllll}\text { Strongly disagree } & 1 & 2 & 3 & 4 & 5 & 6 & \text { Strongly agree }\end{array}$ 8) Overall, I have confidence in accepting responsibility for patients' care under the current handover system

$\begin{array}{lllllllll}\text { Strongly disagree } & 1 & 2 & 3 & 4 & 5 & 6 & \text { Strongly agree }\end{array}$ 9) How could handover be improved?

\section{Transfer of clinical information (audiotape data)}

Following the introduction of ISBAR, handovers showed significantly greater communication of clinical information, with a mean of 10.4 core data categories handed over out of a possible 19 categories, compared to 9.2 categories pre-ISBAR $(p=0.004,95 \%$ CI 0.36 to 1.91$)$. Analysis of the change in individual data categories is presented in table 3 . Thirteen of the 19 categories were handed over with increased frequency following the introduction of ISBAR, but the increase reached statistical significance in only four of the 19 categories. There was a significant increase in the communication of ward, bed, differential diagnosis, and registrar/consultant to be contacted.

Table 2 Exit survey

1) The new handover system is time efficient

$\begin{array}{lllllllll}\text { Strongly disagree } & 1 & 2 & 3 & 4 & 5 & 6 & \text { Strongly agree }\end{array}$ 2) The new handover system is consistent for each patient

$\begin{array}{lllllllll}\text { Strongly disagree } & 1 & 2 & 3 & 4 & 5 & 6 & \text { Strongly agree }\end{array}$ 3) Usually, the amount of information about each patient handed over to me is sufficient to meet my needs (neither too little nor too much)

$\begin{array}{lllllllll}\text { Strongly disagree } & 1 & 2 & 3 & 4 & 5 & 6 & \text { Strongly agree }\end{array}$ 4) Critical patient information is often omitted at handover

$\begin{array}{lllllllll}\text { Strongly disagree } & 1 & 2 & 3 & 4 & 5 & 6 & \text { Strongly agree }\end{array}$ 5) Patient information is often structured poorly during handover

$\begin{array}{lllllllll}\text { Strongly disagree } & 1 & 2 & 3 & 4 & 5 & 6 & \text { Strongly agree }\end{array}$ 6) During most handovers, I am informed which patients are unstable or require more urgent attention

$\begin{array}{lllllllll}\text { Strongly disagree } & 1 & 2 & 3 & 4 & 5 & 6 & \text { Strongly agree }\end{array}$ 7) Overall, I have confidence in accepting responsibility for patients' care under the current handover system

$\begin{array}{lllllllll}\text { Strongly disagree } & 1 & 2 & 3 & 4 & 5 & 6 & \text { Strongly agree }\end{array}$ 8) Overall, ISBAR and the education programme have improved handover

$\begin{array}{llllllll}\text { Strongly disagree } & 1 & 2 & 3 & 4 & 5 & 6 & \text { Strongly agree }\end{array}$ 9) The new ISBAR system is sustainable

$\begin{array}{lllllllll}\text { Strongly disagree } & 1 & 2 & 3 & 4 & 5 & 6 & \text { Strongly agree }\end{array}$ 10) In my opinion, the new ISBAR system improves patient care and safety after hours

$\begin{array}{llllllll}\text { Strongly disagree } & 1 & 2 & 3 & 4 & 5 & 6 & \text { Strongly agree }\end{array}$ 11) The handover workshop improved my confidence and skills in handover $\begin{array}{lllllllll}\text { Strongly disagree } & 1 & 2 & 3 & 4 & 5 & 6 & \text { Strongly agree }\end{array}$ 12) How could handover be improved?

13) How has ISBAR improved/impaired handover? 
Table 3 Audiotape results on handover of core data categories pre- and post-ISBAR

\begin{tabular}{|c|c|c|c|c|}
\hline \multirow[b]{2}{*}{ Category } & \multicolumn{2}{|c|}{$\begin{array}{l}\text { Percentage of } \\
\text { handovers in which } \\
\text { category was } \\
\text { handed over }(\%)\end{array}$} & \multirow[b]{2}{*}{$\begin{array}{l}\text { Change } \\
(\%)\end{array}$} & \multirow[b]{2}{*}{$\begin{array}{l}\text { Significance } \\
\text { (p value) }\end{array}$} \\
\hline & $\begin{array}{l}\text { Pre- } \\
\text { ISBAR }\end{array}$ & $\begin{array}{l}\text { Post- } \\
\text { ISBAR }\end{array}$ & & \\
\hline Age & 49 & 55 & +6 & NS (not significant) \\
\hline Bed & 32 & 46 & +14 & 0.012 \\
\hline Full name & 86 & 85 & -1 & NS \\
\hline MRN & 39 & 48 & +8 & NS \\
\hline Ward & 68 & 95 & +27 & $>0.001$ \\
\hline Current issue & 89 & 93 & +4 & NS \\
\hline Examination findings & 35 & 41 & +6 & NS \\
\hline Relevant test results & 63 & 54 & -9 & NS \\
\hline Stability/level of concern & 30 & 38 & +8 & NS \\
\hline Vital signs & 39 & 49 & +10 & NS \\
\hline Resuscitation status & 13 & 11 & -2 & NS \\
\hline Admission diagnosis & 68 & 68 & 0 & NS \\
\hline Relevant PMH & 52 & 59 & +7 & NS \\
\hline Differential diagnosis & 10 & 18 & +8 & 0.049 \\
\hline Likely diagnosis & 41 & 42 & +1 & NS \\
\hline Management done & 76 & 85 & +9 & NS \\
\hline Who to contact & 28 & 43 & +15 & 0.005 \\
\hline Pending test results & 29 & 28 & -1 & NS \\
\hline What needs to be done & 21 & 21 & 0 & NS \\
\hline
\end{tabular}

MRN, medical record number; PMH, past medical history.

\section{Duration of handover (audiotape data)}

The average duration of handover per patient did not significantly change with ISBAR (100.5 s pre- and $101.3 \mathrm{~s}$ post-ISBAR, $\mathrm{p}=0.894$ ).

\section{DISCUSSION}

This study is the first to examine the effects of introducing the ISBAR tool into JMO handover. Our results show that overall JMOs believed handover was improved by the use of ISBAR. They felt more confident in giving and receiving handover, which we would hope translates into improved accountability and responsibility for patient care, a key purpose of handover. Furthermore, JMOs perceived benefits in patient care and safety following introduction of the ISBAR tool. These results are consistent with studies of ISBAR in other settings, where it has been shown to increase communication content, improve the structure and consistency of delivered information, and ultimately enable recipients to feel better prepared with essential information. ${ }^{12} 1920$ Several hospitals around Australia are starting to use ISBAR in contexts such as emergency departments, nursing, and interhospital transfers.
This study also showed that ISBAR is time neutral, with no change in the duration of individual patient handovers. A time efficient handover tool is important for the uptake of ISBAR into a real clinical setting. A study on the use of ISBAR in telephone communication also found that it was time neutral, ${ }^{19}$ and it has been shown to reduce the duration of nursing handover. ${ }^{21}$

Overall, the mean number of core data categories handed over increased significantly following the introduction of ISBAR, suggesting greater communication of key clinical information. Of the four categories reaching statistical significance, improved handover of differential diagnosis and who to contact were regarded by JMOs as having the potential to improve patient safety. Nine other categories showed a trend towards increased handover but did not reach statistical significance, perhaps because they already showed high frequency of handover at baseline (ie, they were already being handed over well). Categories such as resuscitation status and pending test results, which were handed over with low frequency at baseline, did not show noticeable change following ISBAR introduction, which may be because they are not always relevant to a patient's current situation.

The study group chose 19 core data categories as a marker of data transfer. These categories conform to minimum datasets for clinical handover, ${ }^{22}$ and also cover key areas of inadequate handover which have been identified in studies in US hospitals. ${ }^{5}$ Use of these categories to measure the overall quality of handover (a sophisticated and complex skill) carries some imprecision, and an increase in total information does not necessarily equate to improved patient care. This study was not designed to assess whether the ISBAR tool improves clinical outcomes, and a much larger study would be required to correlate a change in handover practice with a decrease in hospital adverse event reporting. One study that did attempt to link improved communication to reduced rates of adverse events found that after implementation of ISBAR, the rate of adverse events was reduced from a baseline of 89.9 per 1000 patient days to

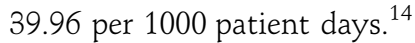

It was gleaned from the JMO feedback and comments in this study that JMOs value handover education and desire more constructive feedback from seniors during handover. Despite this, study authors were perplexed by the poor attendance at the education session run as part of this study, even though those who did attend commented they found it beneficial. The reasons for the poor attendance are multifactorial, including competing clinical demands and a lack of awareness about the importance of handover, and reflect the practical difficulties of implementing education programmes in a hospital setting. In addition, in an attempt to demonstrate a realistic effect of ISBAR which could be replicated in other hospital settings, we encouraged use of ISBAR through posters and lanyards, rather than strictly enforcing its usage.

Table 4 Survey responses on aspects of handover compared pre-ISBAR and post-ISBAR

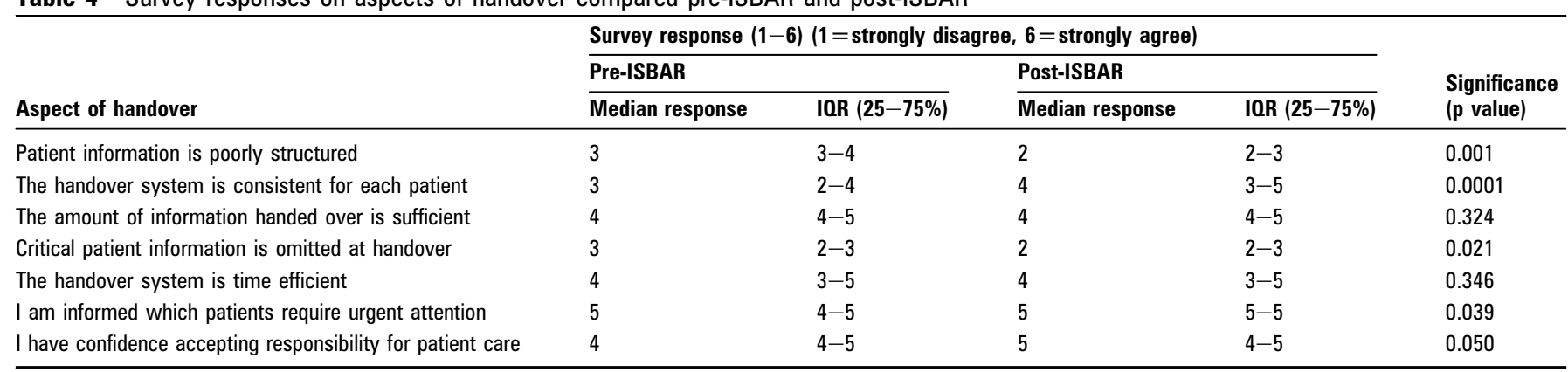




\section{Main messages}

JMOs perceive handover to be improved by the ISBAR tool.

- The ISBAR handover tool improves transfer of key clinical information in a time neutral fashion.

- A simple $1 \mathrm{~h}$ handover education session led to measurable improvements in handover.

- Consideration should be given to implementation of the ISBAR communication tool in all JMO handover settings.

\section{Further areas of research}

- Longer study on whether the effect on ISBAR on JMO handover is sustained.

- Research regarding the effect of education on which patients to hand over.

- Research correlating handover practices with patient outcomes and safety.

Other limitations of this study include the small sample size, and the short duration, which may have limited the JMOs' familiarisation with ISBAR, and thus potentially decreases the perceived impact of the tool. However, it was necessary to complete the study within one JMO term to allow the same JMOs to be studied pre- and post-ISBAR implementation. Further research is needed to assess the durability of introducing such a communication tool. Furthermore, handover research and education must also address which patients require handover and involve training from senior clinicians.

In conclusion, the ISBAR communication tool improved JMO perception of after-hours handover in a time neutral fashion. An education session on the ISBAR tool is an effective, low cost intervention which can lead to significant improvements in JMO handover without disturbing other established practices within the hospital. We consider that this supports the introduction of handover education as a part of medical student and JMO training, and consideration should be given to implementation of the ISBAR tool in all JMO handover settings.

Acknowledgements Karen Byth Wilson for external assistance with and validation of statistics; and Joy P Taylor, Education Co-ordinator and Assistant to the Director of Prevocational Education and Training, Royal North Shore Hospital, for her contribution to design and coordination of the project.

\section{Competing interests None declared.}

Ethics approval This study was conducted with the approval of the Northern Sydney Central Coast Human Research Ethics Committee.

Provenance and peer review Not commissioned; externally peer reviewed.

\section{REFERENCES}

1. Australian Medical Association. Safe Handover: Safe Patients. Guidance on Clinical Handover for Clinicians and Managers. Canberra: AMA, 2006. http://www. ama.com.au/node/4064.

2. Arora VM, Johnson JK, Meltzer DO, et al. A theoretical framework and competency-based approach to improving handoffs. Oual Saf Health Care 2008;17:11-14.

3. Jorm CM, White S, Kaneen T. Clinical handover: critical communications. Med J Aust 2009;190:S108-9.

4. Bomba DT, Prakash R. A description of handover processes in an Australian public hospital. Aust Health Rev 2005:29:68-79.

5. Arora V, Johnson J, Lovinger D, et al. Communication failures in patient sign-out and suggestions for improvement: a critical incident analysis. Qual Saf Health Care 2005:14:401-7.

6. Leonard $\mathbf{M}$, Graham S, Bonacum D. The human factor: the critical importance of effective teamwork and communication in providing safe care. Qual Saf Health Care 2004;13:185-90.

7. Sandlin D. Improving patient safety by implementing a standardized and consistent approach to hand-off communication. J Perianesth Nurs 2007;22:289-92.

8. Borowitz SM, Waggoner-Fountain LA, Bass EJ, et al. Adequacy of information transferred at resident sign-out (inhospital handover of care): a prospective survey. Oual Saf Health Care 2008:17:6-10.

9. Hohenhaus S, Powell S, Hohenhaus JT. Enhancing patient safety during hand-offs. Standardized communication and teamwork using the 'SBAR' method. Am J Nurs 2006;106:72A-C.

10. Horwitz LI, Moin T, Krunholz HM, et al. Consequences of inadequate sign-out for patient care. Arch Intern Med 2008;168:1755-60.

11. Vidyarthi AR, Arora V, Schnipper JL, et al. Managing discontinuity in academic medical centres: strategies for a safe and effective resident sign-out. J Hosp Med 2006:1:257-66.

12. Woodhall LJ, Vertacnik L, McLaughlin M. Implementation of the SBAR communication technique in a tertiary centre. J Emerg Nurs 2008;34:314-17.

13. Alem $\mathbf{L}$, Joseph $M$, Kethers $S$, et al. Information environments for supporting consistent registrar medical handover. HIM J 2008;37:9-24.

14. Haig KM, Sutton S, Whittington J. SBAR: a shared mental model for improving communication between clinicians. Jt Comm J Qual Patient Saf 2006;32:167-75

15. Cohen MD, Hilligoss PB. The published literature on handoffs in hospitals: deficiencies identified in an extensive review. Qual Saf Health Care Published Online First: Dec 2010. doi:10.1136/qshc.2009.033480.

16. Jorm C, ledema R. Innovative Approaches to Enhancing Clinical Handover. Australian Commission on Safety and Quality in Health Care, 2008. http://www. safetyandquality.gov.au.

17. Wayne JD, Tyagi R, Reinhardt G, et al. Simple standardized patient handoff system that increases accuracy and completeness. J Surg Educ 2008;65:476-85.

18. Australian Commission on Safety and Quality in Health Care. OSSIE Guide to Clinical Handover Improvement. 2009. www.safetyandquality.gov.au.

19. Pope B, Rodzen L, Spross G. Raising the SBAR. How better communication improves patient outcomes. Nursing 2008;38:41-3

20. Marshall S, Harrison J, Flanagan B. The teaching of a structured tool improves the clarity and content of interprofessional communication. Qual Saf Health Care 2009:18:137-40

21. Mikos K. Monitoring handoffs for standardisation. Nurs Manag 2007:38;16-20.

22. National Clinical Handover Initiative: Overarching Minimum Data Set. Royal Hobart Hospital, 2008. www.health.gov.au. 